\title{
Development of method of isolation and purification of PAHs from exposed semipermeable membrane devices (SPMDs) prior to GC-MS analysis
}

\author{
Veronika Klučárováa ${ }^{\text {, Eva Benickáa }}{ }^{\text {, Branislav Vrana }}{ }^{\mathrm{b}}$ \\ a Slovak University of Technology, Faculty of Chemical and Food Technology, \\ Radlinského 9, 81237 Bratislava, Slovakia \\ ${ }^{b}$ Water Research Institute, Nabr. Arm. Gen. L. Svobodu 5, 81249 Bratislava, Slovakia \\ klucarova.veronika@gmail.com
}

\begin{abstract}
Surface water pollution by organic contaminants was investigated using passive sampling by semipermeable membrane devices (SPMDs), based on free transfer of analyte (diffusion) from water into receiving phase of sampler. The work was aimed at isolation method of contaminants from passive samplers extracts and instrumental analysis of polycyclic aromatic hydrocarbons. Gel permeation chromatography after silica gel sample cleanup was used as a method for cleaning the extracts of passive samplers from interfering Triolein, the receiving phase in the samplers. The efficiency of isolation and cleaning was determined for polycyclic aromatic hydrocarbons as a target group of contaminants. Polycyclic aromatic hydrocarbons were determined in the obtained fraction by gas chromatography coupled with mass spectrometry.
\end{abstract}

Keywords: passive sampling, semipermeable membrane devices (SPMD), polycyclic aromatic hydrocarbons (PAH), gel permeation chromatography (GPC), gas chromatography with mass spectrometric detection (GC-MS) of PAHs

\section{Introduction}

Anthropogenic pollution, i.e. by pesticides, organic solvents, technology chemicals, drugs, compounds from technology and domestic waste and their degradation products, represents the major part of environment contamination. The fate of these compounds in environment is variable. Some of them even get without change through cleaning technologies for waste waters. The pollution of surface waters by chemical contaminants can lead to disturbance of water ecosystems, the decline in biotopes and decrease in biodiversity.

Water framework directive 2000/60/EU has a primary aim in preservation of the waters and their conservation for future generations (EU, 2000). Priority pollutants list (EU, 2001) contains 33 compounds or compounds groups that shall be monitored in surface waters in EU, because of their high concentrations in rivers, lakes, and coastal waters. The list contains organic compounds as pesticides, polycyclic aromatic hydrocarbons, benzene, halogenated solvents, flame retardants, polymer additives, tensides, antivegetative preparations and also some metals. The EU directive 2008/105/EU (EU, 2008) states the limits of concentrations (environmental quality standards) in surface waters for 41 chemicals including 33 priority compounds and 8 other pollutants representing high risk for aquatic fauna and flora and also for human health.
Two standards are stated: year average concentration to preserve against longterm and chronic effects, and maximal allowed concentration, to prevent irreversible serious effects to ecosystems in consequence of acute short-term exposition.

All analytical methods used for programs estimating the state of waters must fulfill minimal working criteria including the rules for measurement uncertainty and limits of quantification (EU, 2009). Methods shall be validated and documented in accordance with standard EN ISO/IEC-17025 or other corresponding standards accepted on an international level. The information on environment exposition level shall allow for detection of trends in concentrations. Long term measurements in water provide important information that can be used in evaluation of effects of accepted measures on lowering the emissions (UNEP, 2003, UNEP, 2004).

One of the most important tasks of analytical process is the sampling, because of the errors at sampling can not be corrected by further processing of sample, and by that it influences overall precision of measurements. The method of passive sampling may lead mainly to the simplification of the procedure, by coupling the sampling process with the isolation and pre-concentration of analyte into one step. The next advantage of passive sampling is the smaller amount of organic solvent. Common analytical sampling methods of water, so 
called spot sampling, often do not record the trace amounts, in comparison to passive samplers, that allow the estimation of the time weighted average concentration values of analytes over certain periods of time (Lobpreis 2009) and thus detect the ultratrace amounts. Methods of passive sampling represent integral sampling that can average the outlined data of concentrations of contaminant in water, and monitors the bioavailable fraction of pollutants in water. Conventional methods of monitoring with spot sampling of water determine the total concentration, while passive samplers monitor only dissolved fraction of contaminants, which is directly related to chemical activity in water phase and as such is suitable to describe the contaminant fate in the environment.

Passive sampling represents a technique based on free transfer of analyte from aquatic environment to the receiving phase of passive sampler, as a consequence of difference in chemical potential of analyte in these phases. Transfer of compounds is directed by diffusion laws (Fick's 1st and 2nd law) until the thermodynamic equilibrium is established in a system after long term exposition (Huckins et.al, 2006). When the equilibrium is not yet achieved, the sampler is operated on an integrative approach, and target compounds are continually extracted from water.

The semipermeable membranes on a lipidic base are intended for sampling of hydrophobic compounds. The sampling system was developed by Huckins et al. SPMD is composed of low density polyetylene membrane with dimensions usually $94 \times 2.5 \mathrm{~cm}$ and the thickness from 75 to $85 \mu \mathrm{m}$. The membrane pores are of specific size $1 \times 10^{-9} \mathrm{~m}$, representing close proximity to size of the molecules capable of diffusion through biomembranes. Inside the membrane Triolein, a synthetic fish fat (1,2,3-tri-[cis-9-octadecenoyl]glycerol) is deposited (Huckins et al., 2006). During the exposition, Triolein is the receiving phase into which the accumulation of lipophilic contaminants occurs. After exposition the extracted compounds are isolated by dialysis from the sampler receiving phase, and the extracts are further processed. Adsorption column chromatography and gel permeation chromatography (GPC) are the methods of choice for purification of extracts.

The gel permeation chromatography (GPC), also called size-exclusion chromatography (SEC), is used for separation of molecules according to their size. Distribution of substances occurs between moving parts of the mobile phase, located between grains of gel and moving parts of mobile phase located inside the pores of the gel. The hydrophobic gels and the aromatic, chlorinated and some heterocyclic hydrocarbons as mobile phases are used for compounds insoluble in water. The versatile gels based on silica gel and porous glass are suitable for separation of hydrophilic and hydrophobic compounds (Thomatou et al. 2011). Studies based on GPC isolation of emerging compounds from SPMDs exposed in surface waters utilized Phenogel $5 \AA$ with dichloromethane (Klouda 2003) or BioBeads S-X3 200400 mesh with chloroform (Sabaliunas et al. 2000) for PAU, organochlorinated pesticides and PCBs.

The main aim of this work was to prepare and verify the isolation procedure from samplers for polycyclic aromatic hydrocarbons including the GPC procedure for purification of extracts from Triolein before the analytical determination. The recovery of PAHs from cleaning procedure was determined.

\section{Experimental}

\section{Materials}

The following materials were used:

$\mathrm{D}_{10}$-pyrene $\left(10 \mu \mathrm{g} \cdot \mathrm{mL}^{-1}\right.$ in hexane - Dr. Ehrenstorfer, Germany); $D_{8}$-naphthalene (Dr. Ehrenstorfer, Germany); PAH mix 9 (100 ng. $\mathrm{LL}^{-1}$ in cyclohexane Dr. Ehrenstorfer, Germany), dichloromethane (SupraSolv, Merck, Germany); Triolein (Sigma Aldrich GmbH, Belgium); Suphur.

Gasses for GC-MS/ECD equipment: nitrogen (ECD, Messer Tatragas, Slovakia); helium (6.0, Messer Tatragas, Slovakia).

\section{GPC/SEC calibration kit}

- polystyrenes with nominal molecular weight: $\mathrm{Mp}=162, \mathrm{Mp}=380, \mathrm{Mp}=580, \mathrm{Mp}=770$, $\mathrm{Mp}=990, \mathrm{Mp}=1280, \mathrm{Mp}=2170$ (Agilent Technologies, United Kingdom); etalon solutions.

\section{Solutions for gel permeation chromatography (GPC)} Trioleín $(10,20,50,100,200$ and $500 \mathrm{mg} / \mathrm{mL}$ in dichloromethane).

Sulfur (53 mg/mL in dichloromethane): by dissolution of $0,53 \mathrm{~g}$ of sulfur into $10 \mathrm{~mL}$ by dichloromethane.

PAH mix 9 ( $1 \mathrm{ng} \cdot \mu_{\mathrm{L}}^{-1}$ in hexane): by dilution in cyclohexane of PAH mix 9.

PAH mix 9 with Triolein ( 1 ng. $\mu \mathrm{L}^{-1}$ in hexane): by dilution in cyclohexane of PAH mix 9, with addition of $20 \mu \mathrm{L}$ Triolein to $1 \mathrm{ml}$ of final solution.

\section{Etalon solutions for GC-MS calibration}

PAH mix 9 (0, 5, 10, 50, 100, 200, 400, 600, 800 and $1000 \mathrm{ng} \cdot \mathrm{mL}^{-1}$ in hexane): obtained by dilution of PAH mix 9 solution ( $\left.1 \mathrm{ng} \cdot \mu_{\mathrm{L}^{-1}}\right)$ in hexane.

\section{Instruments and equipment}

The apparatus for GPC (ECOM, Prague, Czech Republic) consisting from: 
- isocratic pump ALPHA 10 Plus, manual injection valve (with loop $500 \mu \mathrm{L}$ ), column Agilent PL Gel 5 m 50 Å, $7.5 \times 300$ mm (79911 GP-500), programmable UV VIS detector SAPPHIRE $600(\lambda=254 \mathrm{~nm})$

- input three-way valve connected before the pump enabling the injection or flushing the column by solvent;

- SPIDER unit for collection of fractions, with output 6-port valve connected behind the detector, for collection of particular fractions;

- data-station Ecomac.

Gas chromatograph with mass spectrometric detection GC-MS with electron impact ionization (EI), including:
- gas chromatograph HP 6890 (Agilent Technologies, Germany) with splitless injector;

- automated liquid sampler HP 7637;

- the column HP-5MS (5\% phenyl-95\% methyl siloxane, HP 19091S-433) $30 \mathrm{~m} \times 0.25 \mathrm{~mm}$ i.d. $\times 0.25 \mu \mathrm{m}$ film of stationary phase (Agilent Technologies);

- detector: mass spectrometer HP 5971 (Agilent Technologies).

The analysis of samples by GC-MS was preceded by calibration in the range $0-1000 \mathrm{ng} \cdot \mathrm{mL}^{-1}$. The working conditions: pulsed splitless injection of $1 \mu \mathrm{L}$ at $250{ }^{\circ} \mathrm{C}$; helium flowrate $1.9 \mathrm{~mL} \cdot \mathrm{min}^{-1}$ constant flow; column temperature program from $70^{\circ} \mathrm{C}(2 \mathrm{~min}$ isothermally), then increase with rate $25^{\circ} \mathrm{C} \cdot \mathrm{min}^{-1}$ to

Tab. 1. The list of measured PAH compounds with characteristic ions for qualitative and quantitative analysis by GC-MS method.

\begin{tabular}{|c|c|c|c|c|}
\hline \multirow{2}{*}{$\begin{array}{l}\text { The name of compound } \\
\mathrm{D}_{10} \text {-Fluoranthene (internal standard) }\end{array}$} & \multirow{2}{*}{$\begin{array}{l}\text { Retention time } \\
\text { [min] } \\
20.63\end{array}$} & \multirow{2}{*}{$\begin{array}{c}\begin{array}{c}\text { Ion for quantification } \\
\mathbf{m} / \mathbf{z}\end{array} \\
212.05\end{array}$} & \multicolumn{2}{|c|}{$\begin{array}{l}\text { Ions for identification } \\
\mathbf{m} / \mathbf{z}\end{array}$} \\
\hline & & & 106.05 & - \\
\hline Terfenyl & 24.11 & 230.05 & 201.95 & 114.95 \\
\hline $\mathrm{D}_{8}$-Naphthalene (surrogate) & 5.30 & 136.00 & - & - \\
\hline Naphthalene & 5.32 & 128.00 & 102.00 & 64.00 \\
\hline Acenaphthylene & 7.91 & 151.95 & 126.05 & 76.05 \\
\hline $\mathrm{D}_{10}$-Acenaphthene (PRC) & 8.37 & 164.00 & 162.05 & 80.05 \\
\hline Acenaphthene & 8.37 & 153.05 & 126.05 & 76.05 \\
\hline Fluorene & 9.84 & 166.05 & 139.00 & 82.55 \\
\hline $\mathrm{D}_{10}$-Fluorene (PRC) & 9.84 & 176.00 & 146.05 & - \\
\hline Phenanthrene & 13.74 & 178.00 & 152.05 & 76.05 \\
\hline $\mathrm{D}_{10}$-Phenanthrene (PRC) & 13.74 & 188.00 & 160.05 & 80.05 \\
\hline Anthracene & 13.96 & 178.00 & 152.05 & 76.05 \\
\hline $\mathrm{D}_{10}$-Anthracene (surrogate) & 13.87 & 188.05 & 160.05 & 80.05 \\
\hline Fluoranthene & 20.75 & 202.05 & 101.00 & 88.00 \\
\hline Pyrene & 22.13 & 202.05 & 101.00 & 88.00 \\
\hline $\mathrm{D}_{10}$-Pyrene(surrogate) & 22.00 & 212.00 & 106.05 & - \\
\hline Benz[a]anthracene & 28.26 & 228.10 & 114.05 & 101.00 \\
\hline $\mathrm{D}_{12}$-Benz[a]anthracene (surrogate) & 28.19 & 240.00 & 236.00 & 120.00 \\
\hline Chrysene & 28.41 & 228.10 & 113.05 & 101.00 \\
\hline $\mathrm{D}_{12}$-Chrysene (PRC) & 28.41 & 240.00 & 236.00 & 120.00 \\
\hline $\mathrm{D}_{12}$-Benzo[a]pyrene (surrogate) & 32.99 & 264.00 & 260.00 & - \\
\hline Benzo[b]fluoranthene & 32.05 & 252.05 & 126.05 & 112.95 \\
\hline $\mathrm{D}_{12}$-Benzo $[\mathrm{k}]$ fluoranthene (surrogate) & 32.07 & 264.00 & 260.00 & - \\
\hline Benzo[k]fluoranthene & 32.13 & 252.05 & 126.05 & 112.95 \\
\hline Benzo[a]pyrene & 33.06 & 252.05 & 126.05 & 112.95 \\
\hline $\mathrm{D}_{12}-\mathrm{Benzo}[\mathrm{e}]$ pyrene $(\mathrm{PRC})$ & 32.80 & 264.00 & 260.00 & - \\
\hline Indeno $[1,2,3$-cd $]$ pyrene & 37.73 & 275.95 & 138.00 & 124.05 \\
\hline Dibenz $[\mathrm{a}, \mathrm{h}]$ anthracene & 37.99 & 278.05 & 139.00 & 124.95 \\
\hline Benzo[ghi]perylene & 38.97 & 275.95 & 138.00 & 124.05 \\
\hline $\mathrm{D}_{12}$-Benzo[ghi]perylene(surrogate) & 38.85 & 288.00 & - & - \\
\hline
\end{tabular}


$150{ }^{\circ} \mathrm{C}$, then at $3{ }^{\circ} \mathrm{C} \cdot \mathrm{min}^{-1}$ to $200{ }^{\circ} \mathrm{C}$, then at $8^{\circ} \mathrm{C} \cdot \mathrm{min}^{-1}$ to $250{ }^{\circ} \mathrm{C}$, then isothermally 20 minutes. The time of analysis was $51.87 \mathrm{~min}$. The MS detector was set to $320^{\circ} \mathrm{C}$ and $70 \mathrm{eV}$ for EI. The measurements were done by selected ion monitoring (SIM) and for each compound 2-3 characteristic ions were used for detection and quantification. The determination of compound in a sample was performed from the peak area for highest characteristic ion in mass spectrum of compound by external calibration method. The list of measured PAH compounds is given in the Table 1 together with their retention times and ions for detection and quantitative analysis.

\section{Results and Discussion}

\section{Calibration of GPC}

The passive samplers processing procedure was optimized for the highest recovery of analytes. The main work was done on GPC process and calibration. The calibration of apparatus for GPC was performed by polystyrene etalons with various main molar mass, listed in Table 2.

The log-linear calibration of molar mass against the retention volume was performed. The resulting equation of calibration was determined:

$$
\log M=-0.5702 \times V+6.3673
$$

where: $M-$ molar mass in $\mathrm{g} \cdot \mathrm{mol}^{-1}, V$ - retention volume in $\mathrm{mL}$.
Tab. 2. Table of polystyrene etalons data.

\begin{tabular}{lccc}
\hline Polystyrene & Molar mass [g.mol $\left.{ }^{-1}\right]$ & $\log \boldsymbol{M}$ & $\boldsymbol{V}[\mathbf{m L}]$ \\
\hline 1 & 162 & 2.21 & 7.41 \\
2 & 380 & 2.58 & 6.53 \\
3 & 580 & 2.76 & 6.21 \\
4 & 770 & 2.89 & 6.05 \\
5 & 990 & 3.00 & 5.89 \\
6 & 1280 & 3.11 & 5.77 \\
7 & 2170 & 3.34 & 5.44 \\
\hline
\end{tabular}

Figure 1 shows the GPC chromatogram of polystyrene etalons which were used to calibrate the instrument. Figure 2 represents the dependence of the elution volume versus the logarithm of molar mass value.

\section{Development of methods for isolation of PAHs in SPMD extracts by GPC}

For the proper isolation of the analytes from Triolein from the extracts of the SPMD samplers, the correct setting of fraction collector was necessary (periods and collected volume fraction). The target analytes were limited by fraction of Triolein at the beginning and by fraction of waste on the end. Solutions of the Triolein were prepared in dichloromethane in concentrations of $10,20,50$, 100, 200 and $500 \mathrm{mg} \cdot \mathrm{mL}^{-1}$ and dichloromethane solution of sulphur was prepared in concentration of $53 \mathrm{mg} \cdot \mathrm{mL}^{-1}$, and they were used to define

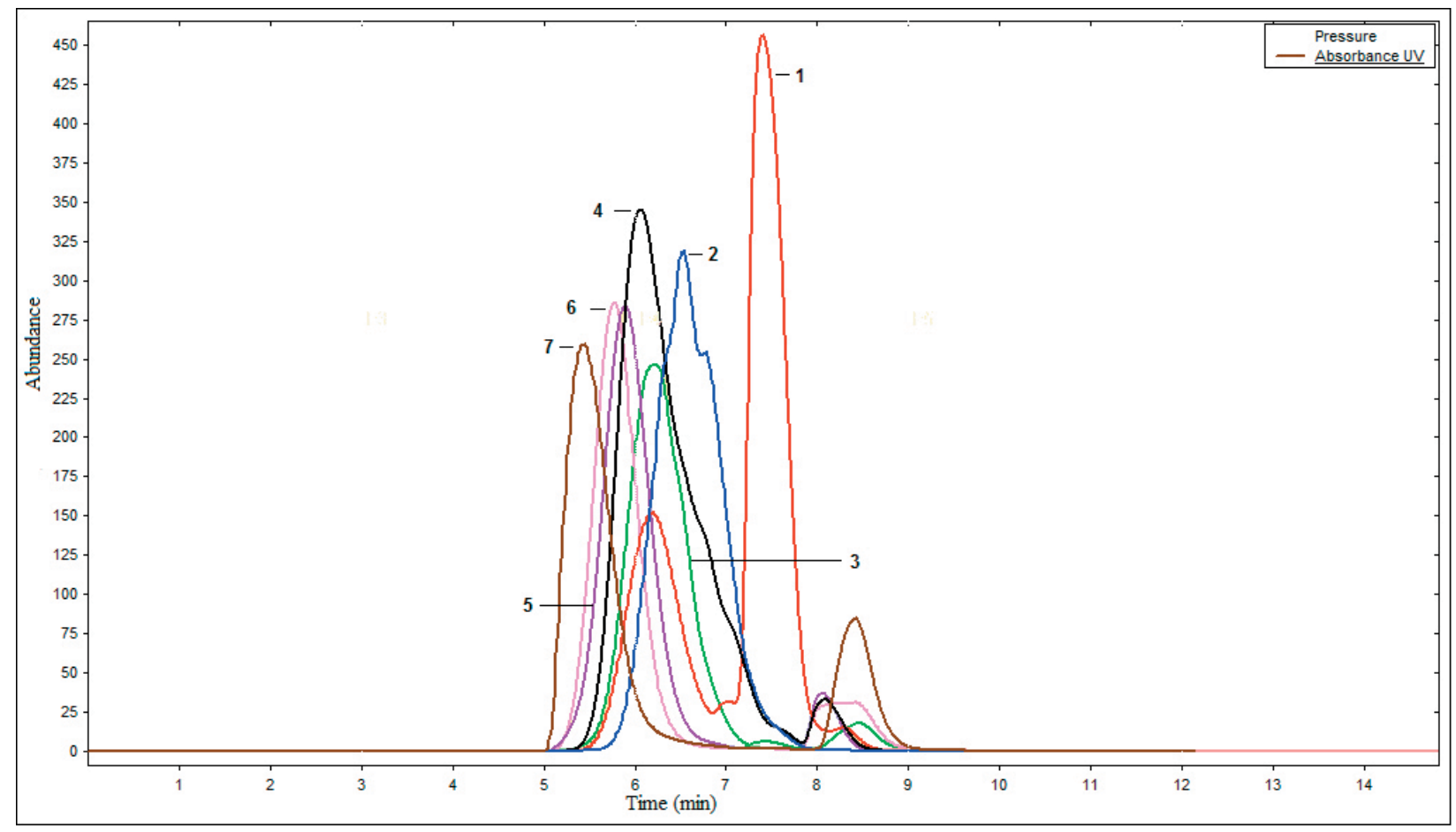

Fig. 1. GPC chromatograms (overlaid) of polystyrene standards. Nominal molecular weight: (1) $\mathrm{Mp}=162$, (2) $\mathrm{Mp}=380,(3) \mathrm{Mp}=580$, (4) $\mathrm{Mp}=770$, (5) $\mathrm{Mp}=990,(6) \mathrm{Mp}=1280$, (7) $\mathrm{Mp}=2170$. 


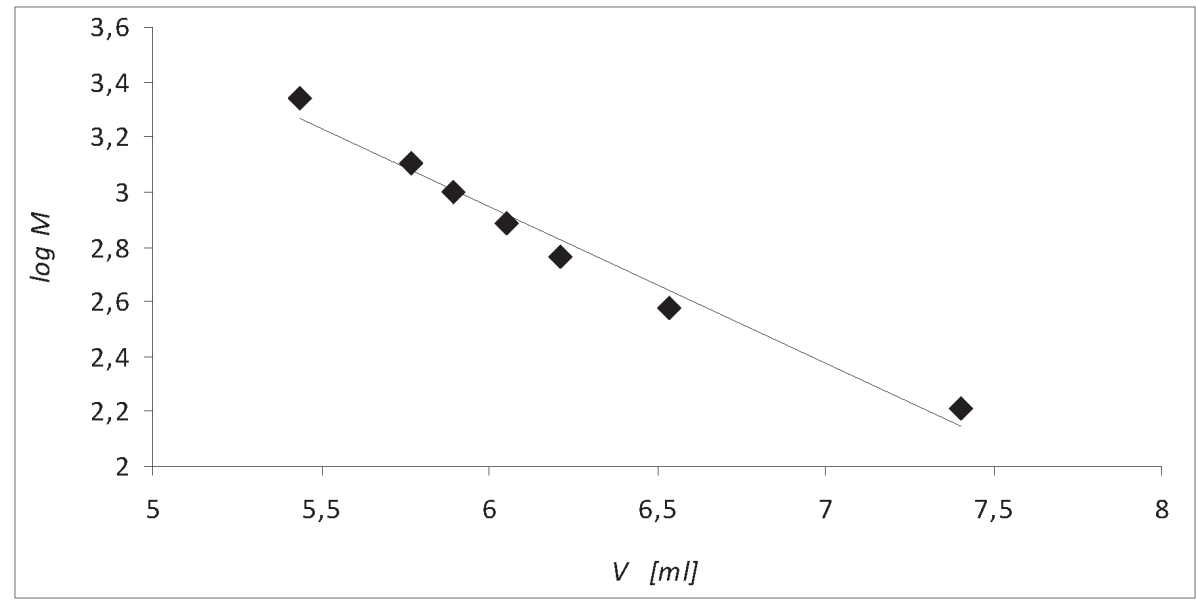

Fig. 2. The dependence of log molar mass $(M)$ versus retention volume ( $V$ ), GPC calibration.

these fractions. Triolein has the largest molar mass $\left(M=885.4 \mathrm{~g} \cdot \mathrm{mol}^{-1}\right)$ from all studied compounds, thus molecules of Triolein spend the shortest time in column, sulphur $\mathrm{S}_{8}$ has a molar mass $\left(M=256.8 \mathrm{~g} \cdot \mathrm{mol}^{-1}\right)$, representing in the solution the form leaving the column as the last compound, as the waste. The analytes have molar masses in the range of values from $M=128.0 \mathrm{~g} \cdot \mathrm{mol}^{-1}$ (naphthalene) to $M=276 \mathrm{~g} \cdot \mathrm{mol}^{-1}$ (benzo [ghi] perylene, all molecular weights are shown in Table 3).

The separation from Triolein was a key problem, because of its interference with the identification and quantification of PAHs using GC-MS. The
PAH mix 9 solutions were prepared with Triolein and cleaned by GPC, to measure the effectiveness of the separation from Triolein. Gradually the method was modified so as to obtain the highest possible yield of the analytes and the most successful isolation of Triolein, Table 4.

The clean-up from Triolein was performed by GPC, from a volume of $500 \mu \mathrm{L}$ of sample. The separation on a column was achieved with mobile phase dichloromethane with flowrate $1 \mathrm{~mL} \cdot \mathrm{min}^{-1}$.

Gravimetric determination was based on comparison of mass of Triolein passed into the isolated second fraction. The difference from injected

Tab. 3. Physical properties of polycyclic aromatic hydrocarbons.

\begin{tabular}{|c|c|c|c|c|}
\hline Compound & $M\left[\mathrm{~g} \cdot \mathrm{mol}^{-1}\right]$ & $\log K_{o w}{ }^{1}$ & $\log K_{s w}{ }^{2}$ & $\mathbf{S}\left[\mathrm{g} \cdot \mathrm{m}^{-3}\right]^{3}$ \\
\hline Naphthalene & 128.00 & 3.37 & 3.37 & 30.0 \\
\hline Acenaphthylene & 152.19 & 4.00 & 4.09 & 16.1 \\
\hline Acenaphthene & 154.21 & 3.92 & 4.00 & 3.8 \\
\hline Fluorene & 166.22 & 4.18 & 4.26 & 1.9 \\
\hline Phenanthrene & 178.23 & 4.57 & 4.62 & 1.1 \\
\hline Anthracene & 178.23 & 4.54 & 4.59 & 0.045 \\
\hline Fluoranthene & 202.25 & 5.22 & 5.10 & 0.26 \\
\hline Pyrene & 202.25 & 5.18 & 5.07 & 0.132 \\
\hline Benz[a]anthracene & 228.29 & 5.91 & 5.46 & 0.011 \\
\hline Chrysene & 228.00 & 5.86 & 5.43 & 0.0019 \\
\hline Benzo[b]fluoranthene & 252.00 & 5.90 & 5.45 & 0.0015 \\
\hline Benzo $[k]$ fluoranthene & 252.00 & 5.90 & 5.45 & 0.0008 \\
\hline Benzo[a]pyrene & 252.31 & 6.04 & 5.51 & 0.0038 \\
\hline Indeno[1,2,3-cd $]$ pyrene & 276.00 & 6.50 & 5.64 & 0.0005 \\
\hline Dibenz $[\mathrm{a}, \mathrm{h}]$ anthracene & 278.00 & 6.75 & 5.68 & 0.0005 \\
\hline Benzo[ghi]perylene & 276.00 & 6.50 & 5.64 & 0.0003 \\
\hline
\end{tabular}

${ }^{1}$ partition coefficient in the system octanol/water.

${ }^{2}$ partition coefficient in the system SPMD sampler/water.

${ }^{3}$ solubility in water (Booij et al. 2007). 
Tab. 4. List of GPG methods for isolation of PAHs.

\begin{tabular}{cccccccccc}
\hline \multirow{2}{*}{ Method } & Pressure & $\begin{array}{c}\text { Flow } \\
{\left[\mathbf{m L} \cdot \mathbf{m i n}^{-1}\right]}\end{array}$ & \multicolumn{2}{c}{$\begin{array}{c}\text { Fraction of Triolein } \\
{[\mathbf{m i n}]}\end{array}$} & $\begin{array}{c}\text { Folume } \\
{[\mathbf{m L}]}\end{array}$ & $\begin{array}{c}\text { Time } \\
{[\mathbf{m i n}]}\end{array}$ & $\begin{array}{c}\text { Volume } \\
{[\mathbf{m L}]}\end{array}$ & $\begin{array}{c}\text { Time } \\
{[\mathbf{m i n}]}\end{array}$ & $\begin{array}{c}\text { Volume } \\
{[\mathbf{m L}]}\end{array}$ \\
\hline 1 & 2 & 1 & $0.0-6.8$ & 6.8 & $6.8-9.8$ & 3 & $9.8-15.0$ & 5.2 \\
2 & 2 & 1 & $0.0-6.8$ & 6.8 & $6.8-10.2$ & 3.4 & $10.2-15.0$ & 4.8 \\
3 & 2 & 1 & $0.0-6.6$ & 6.6 & $6.6-9.8$ & 3.2 & $9.8-15.0$ & 5.2 \\
4 & 3 & 1 & $0.0-6.6$ & 6.6 & $6.6-10.3$ & 3.7 & $10.3-15.0$ & 4.7 \\
\hline
\end{tabular}

Triolein amount was supposed to be contained in the first fraction. The method 4 from Table 4 was used for the separation. A mixture of hydrocarbons PAH mix 9 ( 1 ng. $\mu \mathrm{L}^{-1}$ of hexane) was used with addition of Triolein in the amount of $20 \mu \mathrm{L}$, equivalent to the average weight of Triolein $0.0166 \mathrm{~g}$, as calculated from repeated measurements of $20 \mu \mathrm{L}$ Triolein. The solution was cleaned with GPC and the result was almost $86 \%$ average recovery of Triolein in the first fraction, ranging from 81 to $92 \%$ from repeated measurements, by gravimetric determination of Triolein passed into the second fraction. The isolated fraction containing PAHs collected in a test tube was evaporated by a gentle stream of nitrogen after the addition of $100 \mu \mathrm{l}$ of n-nonane, preventing the evaporation of target compounds, to a volume approximately $100 \mu \mathrm{l}$ and reconstituted in a hexane to $1 \mathrm{ml}$.

The GC-MS quantification of polycyclic aromatic hydrocarbons was performed with the internal standard method, with addition of internal standard $\mathrm{D}_{10}$-Fluorantene solution in hexane $\left(4 \mu \mathrm{g} \cdot \mathrm{mL}^{-1}\right)$ in the amount of $50 \mu \mathrm{L}$ to $1 \mathrm{ml}$ of calibration solutions of PAH mix 9 and to samples from recovery experiment. All calibration dependences were linear in range up to $1000 \mathrm{ng} \cdot \mathrm{mL}^{-1}$ of individual PAHs with correlation coefficients ranging from 0.968 for dibez[a,h]anthracene (exception) and 0.990 for benzo[k]fluorantene, benzo[b]fluorantene, benzo[a] pyrene and indeno $[1,2,3-\mathrm{cd}]$ pyrene, to 0.999 for fluorene, fenanthrene, anthracene, fluorantene and pyrene.

Figure 3 presents the chromatogram of calibration solution of PAH mix 9 with concentration of individual compounds $200 \mathrm{ng} \cdot \mathrm{mL}^{-1}$. The concentration of internal standard $\mathrm{D}_{10}$-fluorantene was $200 \mathrm{ng} \cdot \mathrm{mL}^{-1}$.

Table 5 presents the recovery values of PAH by GPC cleaning, which was determined by model samples. The average recoveries of individual PAHs with exception of naphthalene were determined from 42 to $59 \%$. The loss of compounds may be due to evaporation in the nitrogen atmosphere to very low volumes and by rotary vacuum evaporator. Even with the presented recovery, the repeatability is

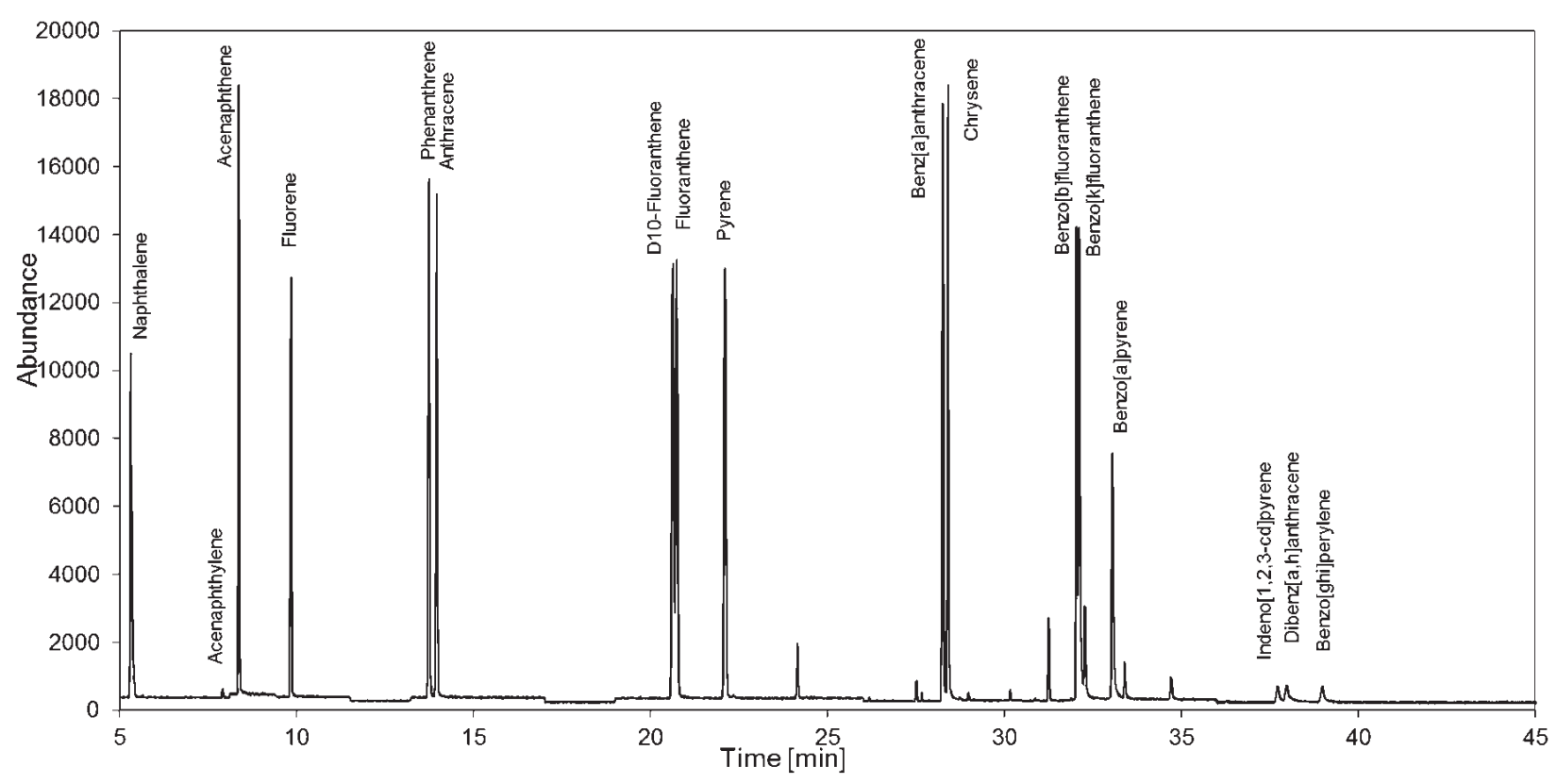

Fig. 3. Chromatogram of calibration solution with analyte concentrations $200 \mathrm{ng} \cdot \mathrm{mL}^{-1}$. Concentration of internal standard $\mathrm{D}_{10}$-Fluoranthene was $200 \mathrm{ng} \cdot \mathrm{mL}^{-1}$. 
Tab. 5. Recovery of individual PAHs from repeated experiments after GPC cleaning.

\begin{tabular}{|c|c|c|c|c|c|c|c|c|}
\hline \multirow{2}{*}{ Compound } & \multicolumn{6}{|c|}{ Recovery [\%] } & \multirow{2}{*}{$\begin{array}{c}\text { Average } \\
{[\%]}\end{array}$} & \multirow{2}{*}{$\begin{array}{c}\text { Coefficient } \\
\text { of variance }[\%]\end{array}$} \\
\hline & 1 & 2 & 3 & 4 & 5 & 6 & & \\
\hline Acenaphthylene & 43 & 42 & 48 & 42 & 49 & 51 & 46 & 9 \\
\hline Acenaphthene & 44 & 44 & 50 & 45 & 51 & 54 & 48 & 9 \\
\hline Fluorene & 49 & 46 & 52 & 55 & 57 & 62 & 53 & 11 \\
\hline Phenanthrene & 50 & 47 & 52 & 61 & 64 & 66 & 57 & 14 \\
\hline Anthracene & 49 & 47 & 52 & 62 & 63 & 65 & 56 & 14 \\
\hline Fluoranthene & 50 & 47 & 53 & 65 & 68 & 68 & 59 & 16 \\
\hline Pyrene & 48 & 47 & 52 & 65 & 67 & 66 & 58 & 16 \\
\hline Benz[a]anthracene & 43 & 45 & 50 & 63 & 62 & 58 & 54 & 16 \\
\hline Chrysene & 45 & 47 & 52 & 64 & 65 & 61 & 56 & 16 \\
\hline Benzo[b]fluoranthene & 42 & 44 & 47 & 57 & 48 & 44 & 47 & 12 \\
\hline Benzo $[k]$ fluoranthene & 46 & 53 & 55 & 59 & 59 & 50 & 54 & 10 \\
\hline Benzo[a]pyrene & 42 & 47 & 52 & 54 & 51 & 42 & 48 & 11 \\
\hline Indeno $[1,2,3$-cd $]$ pyrene & 43 & 46 & 54 & 50 & 44 & 33 & 45 & 16 \\
\hline Dibenz[a,h]anthracene & 46 & 47 & 55 & 49 & 43 & 32 & 45 & 17 \\
\hline Benzo[ghi]perylene & 39 & 44 & 49 & 47 & 41 & 30 & 42 & 16 \\
\hline
\end{tabular}

quite acceptable with coefficient of variance $<17 \%$. With exception of naphthalene the losses were in the interval of tolerance accepted in trace analysis.

\section{Conclusion}

The method for isolation of PAHs from passive samplers extracts by gel permeation chromatography was found to be suitable procedure. The successful separation of SPMD receiving medium - Triolein, with the $80 \%$ average recovery of Triolein, was positive result with respect to following GC-MS analysis. The recovery of individual PAHs with exception of naphthalene were determined from 42 to $59 \%$ that was in the interval of tolerance accepted in trace analysis.

\section{Acknowledgement}

This research was supported by the EU European Reagional Development Fund (ERDF) from the Operational Programme of Cross-Border Cooperation Slovakia-Austria 2007-2013 (project HESTIA), the scientific agency of the Ministry of Education of the Slovak Republic (project VEGA 1/0483/11).

\section{References}

Booij K, Vrana B, Huckins JN (2007) Comprehensive Analytical Chemistry 48: 141-168.

EU (2000). Directive 2000/60/EC of the European parliament and of the council of 23 October 2000 establishing a framework for community action in the field of water policy. Official Journal of the European Union L327, 1-72.

EU (2008). Directive 2008/105/EC of the European parliament and of the council of 16 December 2008 on environmental quality standards in the field of water policy. Official Journal of the European Union L348, 84-96.

EU (2009). Directive 2009/90/EC of the European parliament and of the council of 31 July 2009 in cordiance with EU Directive 2000/60/EC of the European parliament and of the council, establishing the technical specifications for chemical analysis and monitoring the state of waters. Official Journal of the European Union L201/36.

EU (2001). Decision 2455/2001/EC of 20 November 2001, stating the list of priority pollutants in the filed of water politics. Official Journal of the European Union L331.

Huckins JN, Petty JD, Booij K (2006) In: Monitors of Organic Chemicalsin the Environment. Semipermeable membrane devices. Springer, New York, 2006, ISBN 978-0387-29077-5

Lobpreis T, Vrana B, Dercová K (2009) Chemické Listy 103: 548-558.

Sabaliunas D, Lazutka JR, Sabaliuniene I (2000) Environmental Pollution 2: 251.

Thomatou AA, Zacharias I, Hela D, Konstantinou I (2011) Environmental Science and Pollution Research 7: $1222-1233$.

UNEP (2003). Proceedings, UNEP Workshop to Develop a Global POPs Monitoring Programme to Support the Effectiveness Evaluation of the Stockholm Convention. 24-27.3.2003.

UNEP (2004). UNEP Guidance for a Global Monitoring Programme for Persistent Organic Pollutants 1st Edition. 2004. 